\title{
OS CONTEXTOS DE INFLUÊNCIA POLÍTICA E DE PRODUÇÃO DE TEXTO NO CURRÍCULO NACIONAL BRASILEIRO $^{1}$
}

\author{
Adriana Corrêa ${ }^{2}$ \\ José Carlos Morgado ${ }^{3}$
}

\begin{abstract}
Resumo: Este trabalho desenvolveu-se em torno do currículo nacional brasileiro. Trata-se de um estudo que incidiu na análise da gênese da Base Nacional Comum Curricular (BNCC), procurando compreender a forma como foi concebida, quem iniciou o processo de construção, que grupos operaram e lhe deram suporte político. Nesse contexto, por vezes contraditório, diferentes grupos reivindicam a mobilização, construção e, finalmente, a sua implementação. Os fios e os nós que entretecem o contexto político no âmbito do qual decorreu a sua produção fazem parte da nossa pesquisa, ao longo da qual procuramos desocultar, a partir do Ciclo de Políticas, os contextos de influência política e de produção do texto. Recorremos aos redatores do texto, aos Agentes Públicos e aos membros do Movimento pela Base Nacional Comum Curricular, como interlocutores da amostra, em particular nos sentidos e decisões dos contextos, através de entrevistas e análises de documentos, que corporizaram uma abordagem de natureza qualitativa. Além disso, incidimos também na sua construção, que envolveu a dissolução de fronteiras do global-local, tornando visível alguma volatilidade do próprio processo, permeado por algumas concessões e vontades dos seus protagonistas. Daí o nosso interesse de compreender as diferentes versões do documento, bem como os processos políticos que lhe estiveram subjacentes, sem descurar a influência do fluxo de políticas transnacionais que concorreram para minimizar o papel do Estado, agora baseado em imperativos de eficiência e performatividade, que anunciam a promessa da modernidade. Tais processos, evidenciam os interesses do mercado pretender substituir o Estado nas suas mais elementares funções.Os resultados da investigação apontam para o protagonismo do Movimento pela Base Nacional Comum Curricular, que mobilizou uma série de decisores políticos para que a BNCC entrasse na agenda nacional, contribuindo financeiramente para a sua construção, o que permitiu demonstrar outros interesses subjacentes a esse processo. Sobre a arquitetura curricular do documento aprovado, a epistemologia empregada privilegia a vertente da racionalidade instrumental, respondendo a uma
\end{abstract}

\footnotetext{
${ }^{1} \mathrm{O}$ artigo apresentado, enquadra-se numa pesquisa realizada no âmbito do Programa de Doutoramento em Ciências da Educação, especialidade em Desenvolvimento Curricular, na Universidade do Minho. O período de estudo decorreu de 2016 à 2019 e teve como principal objetivo, analisar as percepções dos atores envolvidos direta ou indiretamente na construção da Base Nacional Comum Curricular (BNCC) ou currículo nacional brasileiro. $\mathrm{O}$ artigo apresentado, revela os resultados da pesquisa.

22Universidade do Minho (adriana03correa@gmail.com)

${ }^{3}$ Universidade do Minho (jmorgado@ie.uminho.pt)
}

$$
\begin{array}{lll}
\text { v. } 22 \text { n. } 50 \quad \text { p. } 19-35 \quad \text { abr/jun } 2020
\end{array}
$$


tradição claramente disciplinar. Além disso, a sua natureza prescritiva apresenta anacronias no tratamento das componentes curriculares, demonstrando uma clara falta de coesão no texto. Por outro lado, a ausência de similaridade entre a norma aprovada e o ordenamento jurídico chama a atenção para a quebra da unidade na Educação Básica, enquanto conjunto orgânico, sequencial e articulado que envolve diferentes etapas de ensino.

Palavras-Chave: Currículo Nacional; Contextos; Política; Reforma Curricular.

\title{
The contexts of political influence and text production in the brazilian national curriculum
}

\begin{abstract}
This work was developed around the curriculum in the Brazilian national. It is a study that focused on the analysis of the genesis of the Common National Curriculum Base (BNCC), trying to understand the way it was conceived, who started the construction process, which groups operated and gave it political support.In this sometimes contradictory context, different groups claim mobilization, construction and, finally, their implementation. The threads and knots that interweave the political context in which its production took place are part of our research, along which we seek to disclose, from the Policy Cycle, the contexts of political influence and text production. We use the writers of the text, the Public Agents and members of the Movement for the Common National Curriculum Base, as interlocutors of the sample, particularly in the senses and decisions of the contexts, through interviews and analysis of documents, which embodied a qualitative approach.In addition, we also focused on its construction, which involved the dissolution of global-local boundaries, making visible some volatility of the process itself, permeated by some concessions and wishes of its protagonists. Hence our interest in understanding the different versions of the document, as well as the underlying political processes, without neglecting the influence of the flow of transnational policies that contributed to minimize the role of the state, now based on imperatives of efficiency and performativity, which they announce the promise of modernity. Such processes highlight the interests of the market in wanting to replace the State in its most elementary functions. The results of the investigation point to the protagonism of the Movement for the Common Curricular Base, which mobilized a series of policy makers to make the BNCC into the national agenda, contributing financially for its construction, which allowed to demonstrate other interests underlying this process.Regarding the curricular architecture of the approved document, the epistemology employed privileges the strand of instrumental rationality, responding to a clearly disciplinary tradition. Moreover, its prescriptive nature presents anachronisms in the treatment of curriculum components, demonstrating a clear lack of cohesion in the text. On the other hand, the absence of similarity between the approved norm and the legal system draws attention to the breakdown of unity in Basic Education, as an organic, sequential and articulated set that involves different stages of teaching.
\end{abstract}

Keywords: National Curriculum; Contexts; Politics; Curriculum Reform. 


\section{INTRODUÇÃO}

O currículo nacional brasileiro tem sido objeto de análise e de julgamentos por parte da sociedade, de entidades, das escolas e dos seus professores, pela complexidade, pelo tamanho e, não menos importante, pelo contexto político em que foi gerado. Estamos convictos de que em nenhum momento da história brasileira tivemos um debate desta magnitude, envolvendo, direta ou indiretamente, tantos atores, nem em que o interesse pelo currículo tenha ocupado tantas e tão diferentes instâncias, o que contribui para reforçar a sua centralidade e inserção na agenda nacional.

Daí o interesse que essa situação despertou em nós, o que nos levou a considerá-la pertinente como objeto de um estudo mais amplo, do qual se dá conta ao longo deste texto.

Assim, na pesquisa que desenvolvemos, o nosso interesse circunscreveu-se aos contextos de influência política e de produção de texto, incidiu na arquitetura do documento e na epistemologia utilizada nesse processo, bem como nos paradigmas e nos discursos ocultos que sinalizaram a sua elaboração. A tentativa de compreender o enredo e as suas linhas de construção permitiunos desocultar a sua gênese, as disputas de grupos e as associações que, dado o seu posicionamento, tiveram grande influência na definição dos pressupostos e das concepções incorporadas no texto.

Para o efeito, o processo de investigação que desenvolvemos, no âmbito de um doutoramento realizado na Universidade do Minho, em Portugal, permitiu-nos percorrer caminhos por vezes sinuosos, num emaranhado de fios que tivemos de desenlear ao longo do percurso, com o intuito de compreender o seu processo de (des)construção. Para tornar essa análise mais circunstanciada, recorremos a uma teoria combinada (MAINARDES, 2006), o que nos permitiu captar as percepções dos sujeitos/atores que protagonizaram a elaboração da BNCC, nomeadamente Especialistas representados por Universidades Públicas e Privadas, Professores da Educação Básica e Técnicos de Secretarias de Educação Estaduais, Agentes Públicos que tinham trabalhado no Ministério da Educação (MEC) em cargos estratégicos, membros do Conselho Nacional de Educação (CNE) e, por fim, pessoas ligadas ao Movimento pela Base Nacional Comum Curricular (MBNC), que representam as grandes fortunas do país com maior representatividade nacional. 
Foi um estudo muito interessante, sobretudo por se desenvolver num contexto marcado por disputas de várias ordens, em que interesses, verdades e vaidades tentaram ocupar espaços de poder e de saber, numa arena complexa.

Além disso, na pesquisa procuramos, também, desvelar os interesses nada ocultos do grupo do MBNC, que representa a iniciativa privada, o que foi extremamente difícil, dada as condições objetivas da pesquisa. Assim se compreende que um dos objetivos do estudo fosse desocultar os propósitos dos grupos privados, que movimentam valores vultuosos no país, procurando averiguar de que forma se construiu o discurso político, colocando o currículo como centro de interesse.

Pelos motivos referidos, a gênese do MBNC também foi escalpelizada. O grupo constituiu-se nos EUA, numa primeira incursão na Universidade de Yale, levando Agentes Públicos e Políticos para manter contato com a equipe que construiu a Common Core, em 2013, e de algum modo iniciar a sensibilização para a sua importância. A partir daí, o grupo desenvolveu iniciativas no sentido de o currículo nacional entrar na agenda como prioridade. Infelizmente, um dos limites da pesquisa foi o de não termos conseguido identificar os nomes das pessoas que participaram da referida viagem.

Com efeito, tendo como referência o Ciclo de Políticas de Ball e Bowe (1992) e dada a recente homologação da BNCC, no nosso estudo utilizamos os dois contextos iniciais de análise - o contexto de influência política e o contexto de produção de texto. Além disso, o currículo nacional foi abordado no âmbito das políticas curriculares, através de um estudo sociológico. Para a compreensão de todo o processo realizamos entrevistas e procedemos a uma análise documental e de material digital, o que nos permitiu compreender a sua necessidade e elaboração. Para concretizar tal desiderato, caracterizamos o período do estudo, de 2015 a 2018, e que incluiu a construção, homologação e implantação do documento na Educação Infantil e no Ensino Fundamental.

\section{O CONTEXTO DE INFLUÊNCIA POLÍTICA}

Na caracterização que realizamos, abordamos a gênese da BNCC, uma vez que algumas narrativas recolhidas apresentavam dados controversos, tornando visíveis disputas por parte dos atores envolvidos na sua produção, quer por protagonismo, quer pela legitimidade do documento, como foi o caso 
do MBNC. Constatamos que o mesmo grupo inicia o debate para que o Plano Nacional de Educação (PNE) tivesse como meta a elaboração de um currículo nacional que, por via normativa, tornaria obrigatório o seu cumprimento.

O grupo do MBNC é constituído por Institutos, Fundações ligadas a empresas e famílias tradicionais do país, como também, empresas de pesquisas, pessoas físicas e de Agentes Públicos e Políticos com grande poder de decisão em reformas educacionais. Procuramos compreender o que levou um grupo tão diverso a perseguir objetivos tão comuns em torno da educação nacional, bem como da definição de um currículo comum. Além do peso econômico do grupo, destaca-se o peso político e as vozes proeminentes que ocuparam o debate, em que Agentes Públicos em cargos estratégicos e pessoas avulsas que costumam aparecer com grande frequência nos media, definiram agendas e propuseram soluções prontas para os problemas educacionais. Popkewitz (1994, p. 199) assevera que "quando as ações dos indivíduos aparecem como naturais, existe uma tendência de perder de vista a forma como agendas e categorias que definem as posições são historicamente formadas”.

O tempo político precisou de ser considerado na pesquisa, uma vez que a mudança de Governo e das equipes do MEC, em 2016, na sequência do impeachment da Presidente Dilma, trouxe para a disputa alguns membros do grupo do MBNC que, entretanto, ascenderam a cargos no MEC e no CNE, o que foi importante para a garantia da continuidade do trabalho e da aprovação do documento. A força majoritária do grupo estava, exatamente, nesses representantes, que tinham poder de decisão e, segundo as narrativas de alguns desses membros, não viram qualquer constrangimento, afirmando ser um movimento legítimo de representação da sociedade civil. Ainda que o MBNC não tenha tido qualquer participação direta nos textos, a sua influência fica marcada pelas assessorias internacionais, em que prevaleceram os modelos propostos e a própria agenda.

Assim, a necessidade de assediar os Agentes Públicos e Políticos, que tinham oportunidade e peso político na aprovação do documento, foi extremamente importante e necessária. No segundo semestre de 2016 e em 2018, o grupo do MBNC conseguiu que muitos de seus representantes passassem a ocupar cargos estratégicos no Governo e no CNE, o que foi fundamental para a aprovação dos documentos. É relevante referir que a filiação partidária dos membros é distinta, envolvendo pessoas de partidos de 
esquerda, de centro e de direita, o que nos permite intuir que a questão ideológica não foi um problema.

Todo o financiamento do MBNC foi feito pela Fundação Lemann ${ }^{4}$, desde a contratação da assessoria internacional, à organização dos seminários, às pesquisas encomendadas e às viagens, o que lhe conferiu um certo status em todo o processo. Amparados na lógica do capital e das políticas neoliberais, que defendem a diminuição do Estado, ou a existência de um Estado mínimo em prol das soluções do mercado, buscando a "recuperação dos pressupostos da teoria do capital humano” (PACHECO, 2002, p. 74).

Nas entrevistas foi revelada a participação do grupo em todo o percurso de construção, mesmo que com uma aparente discrição, uma vez que não houve um assédio acintoso contra os redatores do texto. De qualquer modo, não era a sua pretensão interferir na discussão mais minuciosa dos componentes curriculares, mas, sem dúvida, prosseguir o seu caminho, centrando-se sobretudo nos processos envolvidos, o que exigiu um contato mais direto com os formuladores das políticas e seus coordenadores, como a pesquisa apontou.

O currículo nacional passou a fazer parte da agenda pública, com a justificativa de pertinência dos indicadores educacionais como estratégia política de todos os protagonistas. Nesse processo, os interesses na definição de conteúdos que pudessem servir de barômetro para as avaliações em larga escala, tendo em conta as orientações dos organismos internacionais, estiveram presentes em todo o debate. No entanto, os grupos privados tinham outros interesses na construção da BNCC, relacionados com benefícios econômicos, quer através da produção de materiais didáticos, quer da formação continuada de professores e gestores, quer, ainda, dos conteúdos digitais disponíveis nos seus portais. Por isso, a reforma do Ensino Médio (EM) serviu para a definição da oferta de educação à distância, onde estavam fortemente organizados e já estavam a ser disseminados, em muitos Estados do país, por meio de convênios.

\footnotetext{
${ }^{4}$ No nosso estudo, merece destaque a Fundação Lemann, sendo objeto de referência em praticamente todas as narrativas dos entrevistados, indicando o seu papel de distinção no MBNC, como responsável pela articulação e o apoio financeiro em todo o processo de construção. Tal Fundação chama à atenção porque não está associada ao seu aglomerado de empresas, mas à fortuna de seu fundador Jorge Paulo Lemann.
} 
Além disso, analisamos os convênios e acordos do MEC estabelecidos com entidades relacionadas com o MBNC durante a construção da BNCC, bem como os valores vultuosos disponibilizados pelo Governo para a implementação do documento e da política do material didático. A análise de documentos permitiu realçar a penetrabilidade que o grupo possui em vários Sistemas de Ensino, revelando a sua influência na forma como se tem movimentado nas redes públicas, atingindo milhares de alunos, de gestores e de professores.

A Fundação Lemann foi a patrocinadora do documento e quem financiou as viagens para os EUA de Agentes Públicos e Políticos, a contratação de pesquisas, da assessoria internacional, dos seminários e eventos e, por último, do Manual de Implementação. Esses patrocínios foram acompanhados de um discurso em que o seu Fundador, um dos homens mais ricos do país, afirmava ter decidido destinar parte de sua fortuna para a filantropia, pelo "civismo" ou pelo "altruísmo", procurando contribuir para a melhoria da educação.

A pesquisa conseguiu, ainda, apurar o grau de intimidade entre o MBNC e os Agentes Públicos, que ofereceram os seus produtos para a construção da BNCC, com a benevolência do Estado, face aos escassos recursos dos Governos para a área educacional. A forma como as empresas privadas se têm preocupado em definir a agenda das atuais políticas públicas é sintomática, podendo, de alguma forma, beneficiar o setor e chamar à atenção para o efeito. Nesse sentido, destacamos a construção do PNE (2014-2024), um bom exemplo em que os grupos privados interferiram na definição de metas e estratégias para a educação nacional, onde as fronteiras do público-privado não possuem medida, com a "redução, diminuição e desnaturalização do setor público que era provido e dirigido pelo Estado” (SACRISTÁN, 2003, p. 60).

Como pressuposto inicial, tínhamos a ideia de que o MBNC tinha tido protagonismo apenas na versão 3 (V3). O que a pesquisa demonstrou, através da análise documental e das entrevistas, foi que o grupo tinha estado presente já no embrião de construção da BNCC. As mudanças do Governo e do CNE acentuaram esse protagonismo, sobretudo quando alguns dos seus membros passaram a fazer parte da redação do documento.

Por sua vez, a implementação da BNCC mereceu destaque na nossa pesquisa, mesmo não tendo sido objeto de estudo, uma vez definido o tempo para os Sistemas de Ensino implementarem. Porém, até ao final de 2018, o 
período da pesquisa, percebemos a forma como o grupo da MBNC se tinha movimentado, estabelecendo "parcerias" para a sua implementação, o que facilitará a oferta dos seus produtos.

\section{O CONTEXTO DE PRODUÇÃO DO TEXTO}

Em relação ao contexto de produção, podemos afirmar que foi marcado por grandes disputas, quando grupos/associações acadêmicas e profissionais respeitadas no país, tais como a ANPAE, a ANPEd ou o CNTE, se opuseram à sua construção. $\mathrm{O}$ facto é que, nesse processo, a discussão suscitou o debate na sociedade, nas escolas, entre pais e professores, o que nos pareceu saudável. Nunca se viu um movimento desta magnitude, mobilizando tantos atores em torno do currículo, colocando inclusive sob dúvida a pertinência de um currículo nacional no país, marcado pela sua diversidade cultural.

Os dados recolhidos sugerem que a gênese da BNCC teve início em 2014, com o documento "Direitos e Objetivos de Aprendizagem e Desenvolvimento" produzido democraticamente, mas sem a intenção de se tornar um currículo nacional. Todo o planejamento produzido pela então Secretaria da Educação Básica foi discutido por entidades que representam diferentes organismos e que, de alguma forma, foi mantido na versão 1 (V1). Nesse processo, foi visível o mal-estar da equipe do MEC, quando sofreu alterações no seu quadro, não reconhecendo o documento que foi designado de "versão silenciada da Base". As agruras durante o processo foram sendo equacionadas, embora perante disputas entre os próprios Agentes Públicos, prevalecendo dissonâncias e a falta de continuidade dos trabalhos, como foi o caso das constantes trocas das equipes do MEC em que cada uma sobrepôs as suas verdades e deu contornos à sua produção.

O nosso interesse incidiu, também, na arquitetura curricular assumida, que revelou um significado em sua tradição, "como conteúdo da escolarização (...), isto é, o seu lado formal” (PACHECO, 2001, p.143), sugerindo uma epistemologia que vem imposta por uma razão universal e de um sujeito único, desconsiderando todos os estudos multiculturais e da pós-modernidade que realçam a necessidade de ter em conta as diferenças.

Nesta ordem de ideias, o racionalismo instrumental proposto no texto da Educação Básica incide na regulação da cultura e na eliminação das diferenças, 
discutidas na perspectiva do multiculturalismo, como sugere Pacheco (2002, p. 94), numa aparente "darwinização pedagógica". As divergentes versões sobre certos temas, tais como sexualidade e gênero, que foram colocados em debate, realçam a perspectiva assumida nas políticas públicas educacionais, em que o Brasil, retrocede ao garantir a sua visibilidade. Aqui, nomeadamente, os grupos de pressão da sociedade mais conservadora e do parlamento venceram as disputas no CNE e no MEC, quando permitiram a retirada de qualquer menção ao assunto.

Nessa amálgama, o texto carece de uma abordagem que transcenda a compartimentação do currículo e seus acessórios em todas as suas formas, o que acreditamos ser credível para o modelo de currículo que se pretendeu implementar. O modelo uniformizado dos conteúdos, relacionados com as competências e as habilidades, reforça a afirmação de uma "pedagogia produtivista que encontra no standard o critério da organização do currículo em função de uma linearidade factível” (PACHECO, 2018, p. 75).

O texto poderia inovar, trazendo uma visão cosmopolita na defesa do direito de aprender e no acesso a diferentes culturas. Porém, a opção de ajustar o currículo nacional às exigências internacionais, tomando de empréstimo outros modelos, como foi o caso da Austrália e dos EUA, ainda sob os efeitos da globalização e das políticas neoliberais, para o atendimento das avaliações em larga escala e dos valores com o peso das competências, não permitiu implementar essa visão cosmopolita. Assim se compreende que o Grupo Gestor da V3 e do Ensino Médio (Ensino Médio) e os seus apoiantes assumam que foi tida em conta a agenda de organismos internacionais que defendem a necessidade de construir currículos por competências para responder às demandas do século XXI, o que foi perseguido pelo grupo, a exemplo de outros países.

Por outro lado, não podemos esquecer-nos de evidenciar que o Brasil, pela sua dimensão e diversidade cultural, características mais eminentes da sua estrutura social, escolariza diferentes povos nas suas 184,1 mil escolas (BRASIL/MEC/INEP, 2017), espalhadas pelas cinco regiões do país, cada uma delas com características distintas e com a sua própria cultura. Ora, o texto da BNCC, ao negar o regionalismo, silenciando o pluralismo étnico e cultural, reforça as desigualdades sociais e educacionais, o que lamentamos, uma vez que contraria toda a legislação em vigor, bem como o seu mérito a esse respeito. 
Neste domínio, é preciso também destacar que na nossa pesquisa foi dado um tratamento específico à dimensão jurídica, que fundamenta as políticas públicas da educação, trazidas para o debate pela necessidade de fundamentar a existência de um currículo nacional. Concordando com Popkewitz (1997, p. 21), quando afirma que a "legislação aumentou o controle direto do Governo sobre as políticas e conteúdos do ensino”, é importante salientar que a quantidade de normativos na área educacional impressiona, sendo ao mesmo tempo controversos. Analisando uma boa parte desses textos, constatamos que, muitas vezes, os desafios colocados não são tangíveis pelos Sistemas de Ensino e pelos professores. Além disso, o novo currículo nacional envolve outras políticas educacionais, referentes à formação de professores, aos materiais didáticos e, não menos importante, à avaliação.

Ainda resultante dessa análise, destacamos que, embora existam algumas determinações importantes no ordenamento jurídico brasileiro, não têm sido respeitados os seus princípios, no que tange os seguintes aspectos:

a) Progressão e sequencialidade da Educação Básica, previstas nas DCNs (Diretrizes Curriculares Nacionais da Educação Básica);

b) Autonomia dos Sistemas de Ensino, conferida pela LDB (Lei de Diretrizes e Bases da Educação), quanto à sua organização;

c) Cotejamento do currículo, contrariando as concepções definidas nas DCNs;

d) Pluriliguismo, previsto na LDB e DCNs.

Em relação à autonomia dos especialistas na escrita do documento, deparamo-nos com a existência de um discurso quase uníssono dos entrevistados, com raras exceções, em que houve uma blindagem, ou mesmo "boicote", ao documento produzido, como foi o caso das versões 1 e 2 (V1/V2), nos componentes de História e de Arte. Conforme confirmaram alguns dos participantes no estudo, foi um novo grupo que assumiu a autoria do documento, produzindo uma nova versão. No caso da V3 e do Ensino Médio, as narrativas sugerem que a coordenação do documento alterava o texto, muitas vezes sem o consentimento dos seus redatores, e que havia uma certa centralização do trabalho, o que gerava desconforto na equipe. Para alguns redatores, a coordenação dos trabalhos acabou por definir o formato pela sua formação acadêmica. 


\section{CONSIDERAÇÕES FINAIS}

O estudo permitiu constatar a existência de uma grande dispersão conceitual, o que, em nossa opinião, foi propositado, sendo difícil para os Sistemas de Ensino elaborarem os seus currículos. Uma dessas situações diz respeito à insistência em relacionar a BNCC com um currículo nacional, ideia que vinha sendo disseminada desde a sua primeira versão, justificada pela necessidade de garantir os mesmos conhecimentos a todos os alunos do país, relacionados com o direito de aprender.

Essa abordagem foi seguida nas versões subsequentes do documento. No entanto, dada a sua natureza e a própria estrutura hierárquica do currículo, neste caso entendido com um conjunto de conteúdos para serem ensinados e de competências e habilidades que poderão/deverão ser testadas, temos a conviç̧ão de que se trata de um currículo nacional. Para Apple (1999, p. 63), “o principal papel de um currículo nacional reside em providenciar uma estrutura que irá permitir o funcionamento do sistema nacional de avaliação”.

O "status normativo" e a "retórica de produção em série" (Goodson, 1995) corroboram a nossa indicação, na medida em que desnudam a sua percepção acerca dos mínimos necessários a ser ensinados e aprendidos, favorecendo o controle do Estado na sua tecnificação. Além disso, concluímos que o carácter prescritivo do documento permite a intervenção "sobre a cultura dos indivíduos e sobre a prática dos professores ao se imiscuir na ordenação pedagógica”, como sugere Sacristán (2000, p. 133).

Sobre a natureza prescritiva do documento, apontamos, ainda, para as antonomias relacionadas com os componentes curriculares, quando não há, por vezes, coerência e o mesmo tratamento. Em alguns casos, são indicadas metodologias, materiais didáticos e outros encaminhamentos didáticopedagógicos, o que, lamentavelmente, ignora a autonomia dos professores. O nível de detalhe do documento aprovado chama à atenção, denotando uma clara centralização curricular e remetendo para formas de controle, que serão perseguidas pelo Estado.

A ausência de similaridade entre a norma aprovada e a previsão constitucional pareceu-nos grave, relativamente a vários pontos que não foram respeitados. O primeiro deles foi o princípio de unidade da Educação Básica na 
BNCC que envolve o sentido de articulação e a progressão das etapas de ensino. Com a reforma do EM o seu texto foi retirado do documento na V3 e posteriormente aprovado, o que levou a críticas contundentes da sociedade organizada nas audiências públicas. A segmentação desse nível de ensino não se coaduna com a indissociabilidade prevista no ordenamento jurídico, seja na LDB, seja nas DCNs, o que para nós é bastante caro, uma vez, que desde 1996, quando da nova LDB, essa organização ficou clara.

Outra situação apontada nas audiências públicas, durante todo o processo de construção da BNCC, está relacionada com o pacto federativo e com a autonomia dos Sistemas de Ensino. Acreditamos que a sua materialização será acidentada, por causa da centralização e da prescrição da arquitetura curricular definida.

Quanto à epistemologia empregada nos documentos, consta-se que seguiu a vertente da racionalidade instrumental, amparada no Rationale de Tyler, com forte tensão nos comportamentos observáveis, com vista à realização da avaliação em larga escala. A inflexão do documento anterior da $\mathrm{V} 1 / \mathrm{V} 2$, não foi tomada como ponto de partida, mantendo a tradição discplinar, com aquilo que Pinar (1995, p.36) identifica como "instrumentalismo perverso". A opção de definir um formato curricular que privilegia os conhecimentos pragmáticos, remete-nos para o perpétuo debate da "pedagogização dos conhecimentos”, já apontado por Varela (1994), mantendo a estrutura disciplinar.

Com a mesma convicção, tomamos como destaque a arquitetura assumida, que potencializa a necessidade das escolas e dos seus professores atingirem a performance requerida, já defendida por Ralph Tyler, na medida que "torna o teórico não só da lógica de Estado, mas também da lógica de mercado, no que diz respeito à construção de políticas curriculares" (PACHECO, 2002, p. 69). Além disso, a prerrogativa de um currículo nacional alinhado pelas avaliações internacionais e, ao mesmo tempo, a vertente que persegue a monitorização dos seus resultados, poderá, inevitavelmente, responsabilizar os professores, julgando-os e caindo na armadilha da culpabilização, como temos visto em outros países.

A tecnologia empregada nos documentos das várias etapas de ensino potencializa as habilidades que devem ser desenvolvidas, reforçando a linguagem técnica do currículo, procurando o controlo dos imputs e outputs (MORGADO, 2003). Para o efeito, o ensino e a sua gestão ganham novamente 
a centralidade do currículo, remetendo para modelos já testados no Brasil, noutras reformas educacionais, como a do período da Ditadura Militar, em que a tônica foi a definição de um mínimo necessário.

O paradigma de competências utilizado, seguindo a tradição americana, destacada por Lopes e Macedo (2002), quando faz a opção pela taxionomia de Bloom, em que pesa o domínio de comportamentos observáveis, reforça a definição pelas teorias da perspectiva americana. A pesquisa procurou, junto dos redatores da V3 e do EM, conhecer as orientações recebidas pelo Grupo Gestor acerca das competências e verificar se seriam capazes de definir o paradigma. As respostas deram conta de que não foi discutido com os redatores o conceito a ser utilizado, fato corroborado quando nas entrevistas não foram capazes de definir um conceito de competência. Por outro lado, o Grupo Gestor não teve a preocupação de adotar uma epistemologia específica durante a construção do documento, sugerindo que "a academia se preocupa com isso", seguindo a vertente americana do conhecimento prático.

Em relação às mudanças na arquitetura dos documentos, podemos assumir que não foram apenas de ordem semântica, como foi sugerido por alguns entrevistados, mas de ordem epistemológica. Mesmo rejeitando a necessidade de definição dos pressupostos que deram sustentação ao documento, as narrativas dos entrevistados procuraram minimizar a sua natureza, o que para nós, pareceu intencional.

A ruptura do processo após o impeachment da Presidente Dilma, e o tempo político de gestação da BNCC, ficou evidenciado quando compreendemos a sua gênese e os interesses que estavam em jogo.

Mesmo alertados pelos sinais contrários à sua construção, por parte do meio acadêmico e de muitas associações científicas, que a rejeitaram desde o seu embrião, em razão do perigo de centralização curricular, ou apontando para os interesses dos grupos privados, não foi possível a retirada do documento, como se tentou, principalmente, na versão do Ensino Médio.

Quanto ao trabalho dos redatores que se prestaram a um esforço hercúleo, na tentativa de contribuir com sua experiência, anos de estudo e de pesquisa, é preciso lembrar que a sua produção foi e está a ser julgada por toda a sociedade. Ao analisar a trajetória acadêmica e profissional de todos os Especialistas da V1/V2/V3 e EM, podemos assegurar que houve um esforço na redação dos documentos, independentemente de questões ideológicas ou de 
outra natureza. Lembramos que nem todos os Especialistas se dispuseram a participar na pesquisa, embora os que contribuíram com suas narrativas trouxessem as memórias do processo vivido, tendo sido através deles que conseguimos alcançar os objetivos do nosso estudo.

Sublinhamos, porém, a vocação do currículo nacional que definiu os conhecimentos/conteúdos, com o seu carácter polifacetado, revelando muito mais os "mínimos" necessários a serem ensinados e aprendidos e questionamos, como Young (2014), a legitimidade dos "conhecimentos poderosos" e a sua distinção dos "conhecimentos dos poderosos". Um questionamento que leva aos desafios teóricos de compreensão das relações de poder-saber, subsumidas em todo o empreendimento da BNCC, pelos seus protagonistas, quando elencaram àquilo que consideraram mais relevante constar no documento. Tal processo é tipificado pela seleção de alguém, ou de um grupo, que julga de forma arbitrária o que deve ser considerado como importante no currículo. Uma primeira pista do que estudamos dá conta da forma como foi pensadaa seleção de alguns conteúdos, em determinados componentes curriculares e a demarcação de posições que geraram críticas do meio acadêmico, como foi o caso da Língua Portuguesa e da História, principalmente.

A natureza epistemológica de algumas áreas foi evidenciada no nosso estudo, tendo sido caracterizada a partir das disputas dos grupos, o que nos permitiu constatar que, pesem embora os seus delineamentos, escolhas e necessidade de integração, isso não impediu a sua fragmentação e a falta de articulação nas etapas de ensino. $\mathrm{O}$ que entendemos que ocorreu pela divisão dos trabalhos dos grupos, narrados pelos seus redatores, em que cada qual, pensou uma etapa de ensino, e no caso do Ensino Fundamental, os anos iniciais e anos finais. Tendo em conta a nossa vocação de pensar as áreas isoladamente, associada à falta de diálogo e de trabalho interdisciplinar, em que as escolhas teóricas levaram ao pragmatismo e ao reforço da tecnificação curricular, em que os conteúdos passam a ter a centralidade.

A pertinência e a importância do currículo nacional para os entrevistados perfilharam os mesmos significados, com predominância para o respeito pelo ordenamento jurídico que exigia a sua existência, como também a tentativa de garantir, de forma equânime, os mesmos conhecimentos a todas as crianças e jovens do país. Independente do grupo de entrevistados, todos realçaram a necessidade de uma BNCC e a ideia de que o seu envolvimento se deu 
justamente pela convicção de que o currículo era uma aposta na tentativa de garantir os direitos de todos os alunos terem as mesmas oportunidades.

No entanto, as visões são controversas, em relação à necessidade de o Brasil ter um currículo nacional nesse formato, bem como relativamente à condução do processo, sobretudo no Ensino Médio, onde pesam as manifestações nas audiências públicas, com críticas ácidas sobre o texto da Reforma dessa etapa de ensino, em que houve a segmentação da Educação Básica. Acresce o fato de o contraste das versões sobre a arquitetura curricular e a epistemologia empregada anunciarem a quebra do significado da BNCC.

Em suma, o debate exaustivo não foi nem será esgotado. Pelo contrário, um outro caminho será trilhado na tradução e construção, pelos professores, dos diversos currículos nos Sistemas de Ensino, pelos professores, tendo em conta as orientações do Governo e das equipes que assumiram o MEC. O que fica de lição desse processo, independente de qualquer julgamento maniqueísta, é o debate gerado na sociedade em torno do currículo e da sua importância. Nele pululam tensões em torno dos elementos que devem constar no currículo, a legitimidade do processo e dos atores que dela fizeram parte e, não menos importante, o papel das Universidades e a sua vinculação à escola pública. No fundo, um conjunto de aspectos que precisam, ainda, de ser estudados.

Por isso, o principal desafio é o de continuarmos a fazer do currículo o centro da reflexão e do debate educativo, o que contribuirá para a sua melhoria e para que a educação se continue a afirmar como um dos principais imperativos democráticos e uma efetiva referência social.

\section{REFERÊNCIAS BIBLIOGRÁFICAS}

APLle, M. W. Políticas Culturais e Educação. Trad. João Menelau Paraskeva. Coleção Ciências da Educação. Porto, Porto Editora, 1999.

BALL, S; BOWE, R. A Reforming Education \& Changing Schools: case studies in policy sociology. London: Routledge, 1992.

BRASIL, Ministério da Educação. Secretaria da Educação Básica. Base nacional comum curricular educação infantil e ensino fundamental. Brasília: MEC. Disponível em: 
http://basenacionalcomum.mec.gov.br/wpcontent/uploads/2018/02/bncc-20dezsite.pdf. Acesso em: 10 nov. 2017.

GOODSON, I. F. Currículo: teoria e história: Petrópolis, RJ: Vozes, 1995.

LOPES, A. C. MACEDO, E. (orgs). Disciplinas e integração curricular: história e políticas. Rio de Janeiro: DP\&A, 2002.

MAINARDES, J. Abordagem do ciclo de políticas: uma contribuição para a análise de políticas educacionais. In: Educ. Soc., Campinas, vol. 27, n. 94, pp. 47-69, jan./abr. 2006.2 Disponível http://www.scielo.br/pdf/es/v27n94/a03v27n94.pdf. Acesso em: 23 abr. 2016.

MORGado, J. C. Processos e práticas de (re) construção da autonomia curricular. Universidade do Minho. Tese de Doutoramento. Braga. Portugal, 2003.

PACHECO. J.A. Teoria curricular crítica: os dilemas (e contradições) dos educadores críticos. Revista Portuguesa de Educação, 14 (1), 49-71, 2001.

PACHECO. J.A. Políticas Curriculares. Porto: Porto Editora, 2002.

PACHECO. J.A. Discursos e lugares das competências em contextos de educação e formação. Coleção Panorama. Porto: Porto Editora, 2011.

PACHECO. J.A. Para uma teoria curricular de mercado. In: PACHECO, J.A.; ROLDÃO, M. Do C.; ESTRELA, M. T. (orgs). Estudos de currículo. Coleção Educação e Formação. Porto: Porto Editora, 2018. pp.58-84.

PINAR, W. Understanding curriculum. Nova York: Peter Lang, 1995.

POPKEWITZ, T. S. História do Currículo, Regulação Social e Poder. In: SILVA, T. T. (org.). O sujeito da educação. Estudos Foucaultianos. Petrópolis, RJ: Ed. Vozes, 1994.

POPKEWITZ, T. S. Reforma educacional: uma política sociológica, poder e conhecimento em educação. Porto Alegre: Artes Médicas, 1997.

SACRISTÁN, J. G. O currículo: uma reflexão sobre a prática (3ª ed.). Porto Alegre: Artmed, 2000. 
SACRISTÁN, J. G. O significado e a função da educação na sociedade e na cultura globalizada. In: GARCIA, R.L. MOREIRA, A. F. (orgs). Currículo na contemporaneidade: incertezas e desafios. São Paulo: Cortez, 2003.

VARELA, J. O estatuto do saber pedagógico. In: SILVA, T. T.. O sujeito da Educação : estudos foucaultianos (pp.87-96). Petrópolis, RJ: Vozes, 1994.

YOUNG, M. Teoria do currículo: o que é e por que é importante. In: Cadernos de Pesquisa. Vol. 44, nº. 151. São Paulo, jan/mar, 2014. Disponível em http://www.scielo.br/pdf/cp/v44n151/10.pdf. Acesso em: 10 nov. 2017.

Recebido em 30/12/2019

Aprovado em 10/03/2019 